\title{
A Metal-Organic Framework Functionalized with Free Carboxylic Acid Sites and its Selective Binding of a $\mathrm{Cl}\left(\mathrm{H}_{2} \mathrm{O}\right)_{4}^{-}$Cluster
}

\author{
Radu Custelcean* and Maryna G. Gorbunova
}

\section{Supporting Information}

Synthesis: A methanol solution of $\mathrm{CuCl}_{2} \cdot 2 \mathrm{H}_{2} \mathrm{O}(3 \mathrm{~mL}, 0.1 \mathrm{mmol}, 0.017 \mathrm{~g})$ was layered over an aqueous solution of $\mathrm{BNA} \cdot \mathrm{HCl} \cdot 2 \mathrm{H}_{2} \mathrm{O}(4 \mathrm{~mL}, 0.2 \mathrm{mmol}, 0.063 \mathrm{~g})$. Blue crystals of 1 were collected after one week and washed with water and methanol. Yield $0.042 \mathrm{~g}$ (60\%). FTIR (KBr): $v=3391$ (m, br), 3086 (m), 3053 (m), 2914 (m, br), 2807 (m, br), 2621 (m, br), 2500 (m, br), 1722 (s), 1607 (m), 1550 (m), 1297 (m) cm². Elemental analysis $(\%)$ calcd for $\left[\mathrm{CuCl}(\mathrm{BNA})_{2}\right] \cdot \mathrm{Cl}\left(\mathrm{H}_{2} \mathrm{O}\right)_{4}$ : $\mathrm{C} 41.48, \mathrm{H} 3.48, \mathrm{~N}$ 8.06, $\mathrm{Cl} 10.20$; found: C 41.77, H 3.70, N 8.29, Cl 10.69. TGA: calcd weight loss for $4 \mathrm{H}_{2} \mathrm{O}$ : $10.36 \%$; found: $10.47 \%$. The powder X-ray diffraction pattern of bulk 1 corresponds to the calculated pattern from single crystal data.

Single Crystal X-ray Crystallography: Data for $\mathbf{1}$ and $\mathbf{2}$ were collected on a Bruker SMART APEX CCD diffractometer with fine-focus $\mathrm{Mo}_{\mathrm{K \alpha}}$ radiation $(\lambda=0.71073 \AA)$, operated at $50 \mathrm{kV}$ and $30 \mathrm{~mA}$. Structure 1 was solved by the Patterson method and structure 2 was solved by direct methods using SHELXTL. ${ }^{[1]}$ Lp and absorption corrections were applied using SADABS. All non-hydrogen atoms were refined anisotropically, except for the disordered chloride in the channels of $\mathbf{1}$, which was refined isotropically. Hydrogen atoms were calculated and placed in idealized positions using a riding model. Hydrogen atoms on the water molecules in $\mathbf{1}$ and on some of the water molecules in $\mathbf{2}$ could not be located and therefore were not included in refinement. 
Crystal data for $1: \mathrm{C}_{6} \mathrm{H}_{6} \mathrm{Cl}_{0.5} \mathrm{Cu}_{0.25} \mathrm{NO}_{3}, M=173.73,0.06 \times 0.05 \times 0.04 \mathrm{~mm}^{3}$, tetragonal, space group $P 4$ (No. 75), $a=b=11.152(2), c=5.586(2) \AA, V=694.7(4) \AA^{3}, Z=4, D_{c}=$ $1.661 \mathrm{~g} / \mathrm{cm}^{3}, F_{000}=355, T=173(2) \mathrm{K}, 2 \theta_{\max }=56.6^{\circ}, 5331$ reflections collected, 1739 unique $\left(R_{\text {int }}=0.0563\right)$, Final GooF $=1.039, R_{1}=0.0575, w R_{2}=0.1415, R$ indices based on 1301 reflections with $I>2 \sigma(I)$ (refinement on $F^{2}$ ), 99 parameters, 1 restraint. No additional symmetry was found upon checking the structure with PLATON, ${ }^{2}$ and the Flack parameter refined to $0.01(3)$, indicating that the correct absolute structure has been found. X-ray structural analysis of different crystals showed that both enantiomorphs are present in the same crystallization batch, as expected from a racemic mixture of starting $\mathrm{BNA} \cdot \mathrm{HCl}$. The chloride ion in the $\mathrm{Cl}\left(\mathrm{H}_{2} \mathrm{O}\right)_{4}{ }^{-}$cluster is disordered, apparently as a results of its low packing coefficient inside the channels. Removal of this chloride and subsequent refinement using SQUEEZE, part of the PLATON program, ${ }^{2}$ yielded 17 residual electrons/unit cell and a void volume of $40.8 \AA^{3}$. Considering that the ionic volume of $\mathrm{Cl}^{-}$is approximately $23.7 \AA^{3}$ (calculated at the B3LYP/6-31G* level), this corresponds to a packing coefficient for chloride of only 0.58 , compared with a typical molecular crystal that has a packing coefficient of $0.7-0.8 .^{3}$

Crystal data for 2: 59:41 racemic twin, $\mathrm{C}_{24} \mathrm{H}_{28} \mathrm{CuN}_{4} \mathrm{O}_{15}, M=676.04,0.15 \times 0.12 \times 0.11$ $\mathrm{mm}^{3}$, monoclinic, space group $P 2_{1}$ (No. 4), $a=11.1005(11), b=11.1138(11), c=$ $12.3051(13) \AA, \beta=110.710(2)^{\circ}, V=1420.0(2) \AA^{3}, Z=2, D_{\mathrm{c}}=1.581 \mathrm{~g} / \mathrm{cm}^{3}, F_{000}=698, T$ $=173(2) \mathrm{K}, 2 \theta_{\max }=56.6^{\circ}, 14620$ reflections collected, 6999 unique $\left(R_{\mathrm{int}}=0.0204\right)$. Final GooF $=1.103, R_{1}=0.0355, w R_{2}=0.0924, R$ indices based on 6946 reflections with $I>2 \sigma$ (I) (refinement on $F^{2}$ ), 430 parameters, 1 restraint. 
(a)

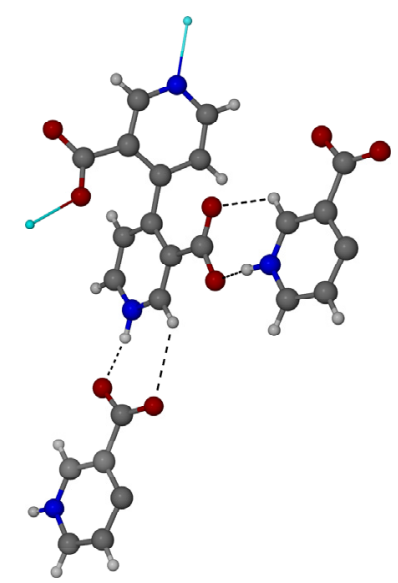

(b)

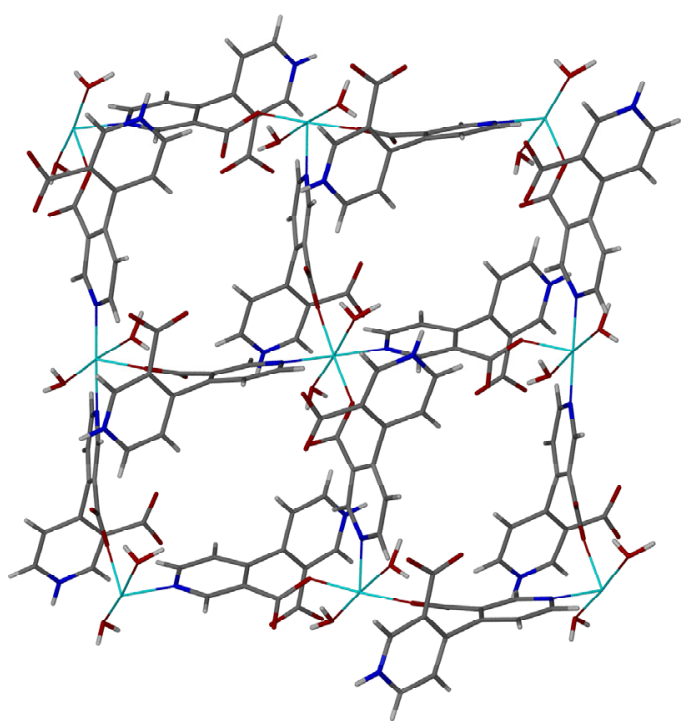

Figure S1. Crystal structure of 2. a) $\mathrm{Cu}$ coordination and hydrogen bonding of the BNA . Half of BNA is deprotonated and coordinates the copper cation via both the pyridine and the carboxylate groups. The other half of BNA is protonated and zwiterionic, with the pyridinium and carboxylate groups engaging in complementary hydrogen bonding. b) Square-grid network involving coordination of $\mathrm{Cu}^{+2}$ by the $\mathrm{COO}^{-}$, pyridine, and two water molecules. The remaining water molecules included in the channels are not shown. The grids are interlinked by pyridinium-carboxylate hydrogen bonds.

[1] SHELXTL 6.12, Bruker AXS, Inc., Madison WI, 1997.

[2] Spek, A. L.; Acta Crystallogr. A 1990, 46, C34.

[3] Dunitz, J. D.; Gavezzotti, A. Angew. Chem. Int. Ed. 2005, 44, 1766. 